\section{G302(P) AN AUDIT ON THE MANAGEMENT OF BRONCHIOLITIS}

${ }^{1} \mathrm{~B}$ Umerji, ${ }^{1} \mathrm{M}$ Yusuf, ${ }^{2} \mathrm{~K}$ Sugumar. ${ }^{1}$ General Medicine, East Lancashire Hospitals Trust, Blackburn, UK: ${ }^{2}$ Paediatrics, Lancashire Hospitals, Preston, UK

\subsection{6/archdischild-2020-rcpch.263}

Bronchiolitis is the most common reason for hospitalization in children under the age of 2 years, resulting in a considerable burden to paediatric services. The mainstay of managing bronchiolitis is supportive through administering oxygen and fluids or feed supplements. Current research suggests that there is no definitive pharmacological treatment showing significant benefit in children with bronchiolitis and that can alter the course of the disease. Such treatments are still widely prescribed by clinicians despite limited evidence of their efficacy. This potentiates an increased likelihood of adverse side effects as well as costs to the NHS. I retrospectively reviewed 90 admissions of bronchiolitis from November 2015 to assess compliance rates with the June 2015 National Institute of Health and Clinical Excellence (NICE) guidelines on bronchiolitis management. NICE guidelines do not recommend the use of pharmacological treatments such as bronchodilators, hypertonic saline, corticosteroids, antivirals and antibiotics among others. Despite the guidelines, at our unit hypertonic saline and salbutamol was prescribed in $16 \%$ of cases, atrovent in $29 \%$, antibiotics in $4 \%$ and steroids in $2 \%$ of cases. Nebulised adrenaline (with or without steroids) and montelukast were not prescribed at all. Thus, compliance rates of managing bronchiolitis with NICE guidelines are above $70 \%$. Further analysis of these groups that received treatments did not reveal any identifiable patterns or trends as to why they are still being prescribed, making it more difficult to propose individualized recommendations to reduce this. Targeted educational strategies may help in improving compliance rates to guidelines.

\section{G303(P) PARENT AND PATIENT PERCEIVED SIDE EFFECTS OF PAEDIATRIC FLEXIBLE BRONCHOSCOPY}

MG Semple, JH Bamforth. 'PhD FRCPCH, Faculty of Health and Life Science, University of Liverpool, Liverpool, UK; ${ }^{2}$ School of Medicine, University of Liverpool, Liverpool, UK

\subsection{6/archdischild-2020-rcpch.264}

Background A literature review was conducted on the side effects of paediatric flexible bronchoscopy services. None directly reported the experience of patients and their parents. The experience of patients and their parents attending the paediatric flexible bronchoscopy service at our children's hospital has not been evaluated.

Aim To evaluate parent and patient reported side effects of paediatric flexible bronchoscopy, in order to improve the paediatric flexible bronchoscopy service offered at the hospital and the validity of its consent.

Methodology Patients, and parents of those patients, undergoing flexible bronchoscopy at this children's hospital between June 2018 and February 2019 were surveyed post-discharge from the flexible bronchoscopy procedure. The survey was created using themes from Monkey Wellbeing, a child-friendly company who create friends and family tests used to determine patient satisfaction across a range of medical and surgical specialities. The survey was completed online and had

\section{Abstract G303(P) Table 1}

$\%$ of Children Experiencing Side Effect

\begin{tabular}{ll}
\hline Cough & 47 \\
Sore Throat & 47 \\
Hoarse Voice & 26
\end{tabular}

separate sections for parents and patients. We asked them to provide information regarding the side effects experienced within the 48 hours following the procedure.

Results There were 16 responses from parents of children aged $0-15$ years. The most common side effects reported among the parental responses were cough, a sore throat and a hoarse voice (see table 1). The 3 most common side effects reported by patients were concordant with this.

No difference was found between the side effects experienced by younger children and older children. 95\% of the parents reported that side effects had no non-trivial effect on their children, and $75 \%$ of children had fully recovered within 24 hours.

Conclusion The side effects most commonly reported were those identified from the literature review. Among the children surveyed, no severe adverse effects occurred following the procedure, and the children generally recovered quickly. This information can be given to parents of children undergoing the procedure in the future in order to improve the validity of consent for paediatric flexible bronchoscopy.

\section{G304(P) A CASE OF RELAPSING POLYCHONDRITIS IN A PAEDIATRIC PATIENT WITH SEVERE AIRWAY INVOLVEMENT - THE CHALLENGES OF LONG TERM AIRWAY \& RESPIRATORY MANAGEMENT}

${ }^{1,2} \mathrm{~T}$ Kothari, ${ }^{1} \mathrm{E}$ Magnussen, ${ }^{3} \mathrm{P}$ Dawson, ${ }^{3} \mathrm{E}$ Al Abadi, ${ }^{2,4} \mathrm{M}$ Elloy, ${ }^{5} \mathrm{~A}$ Sridhar, ${ }^{1} \mathrm{~S}$ Kapoor, ${ }^{1} S$ Bandi, 1,2,6 I Ahmed. 'Paediatrics, Leicester Childrens Hospital, Leicester, UK; ' ${ }^{2}$ Paediatric Respiratory, Leicester Childrens Hospital, Leicester UK; ${ }^{3}$ Paediatric Rheumatology, Birmingham Childrens Hospital, Birmingham, UK; ${ }^{4}$ Paediatric ENT, Leicester Childrens Hospital, Leicester, UK; ${ }^{5}$ Paediatric Rheumatology, Leicester Childrens Hospital, Leicester, UK; ${ }^{6}$ University of Leicester, Leicester, UK

10.1136/archdischild-2020-rcpch.265

Background Relapsing polychondritis (RP) in childhood is a rare multi-system disease characterised by inflammation of multiple cartilages. Progressive destruction of cartilaginous tissues in patients with tracheobronchial involvement can lead to life threatening exacerbations.

Diagnosis in children and young people is often delayed due to rarity of this condition although the clinical course is often more severe than in adults with a higher incidence of laryngotracheobronchial involvement.

Case Report A 14-year-old of African descent presented to the children's hospital with evidence of auricular inflammation, anterior rib pain and red, painful eyes. She had raised inflammatory markers and was treated with broad-spectrum antibiotics. RP was suspected and high dose oral steroids were commenced, improving all symptoms.

On weaning steroids, she quickly relapsed and presented with upper airway problems including stridor, barking cough and increased work of breathing. Initial flexible nasendoscopy showed interarytenoid and subglottic oedema and likely 